\title{
Prognostic implication of SYT-SSX fusion type in synovial sarcoma: A multi-institutional retrospective analysis in Japan
}

\author{
SATOSHI TAKENAKA ${ }^{1,2}$, TAKAFUMI UEDA ${ }^{3}$, NORIFUMI NAKA ${ }^{2}$, NOBUHITO ARAKI $^{2}$, \\ NOBUYUKI HASHIMOTO ${ }^{1}$, AKIRA MYOUI ${ }^{1,4}$, TOSHIFUMI OZAKI ${ }^{5}$, TOMITAKA NAKAYAMA ${ }^{6}$, \\ JUNYA TOGUCHIDA ${ }^{6,7}$, KAZUHIRO TANAKA $^{8}$, YUKIHIDE IWAMOTO ${ }^{8}$, AKIHIKO MATSUMINE ${ }^{9}$, \\ ATSUMASA UCHIDA ${ }^{9}$, MAKOTO IEGUCHI ${ }^{10}$, MITSUNORI KAYA ${ }^{11}$, TAKURO WADA ${ }^{11}$, \\ ICHIRO BABA $^{12}$, IKUO KUDAWARA ${ }^{3}$, YASUAKI AOKI ${ }^{13}$ and HIDEKI YOSHIKAWA ${ }^{1}$
}

\begin{abstract}
${ }^{1}$ Department of Orthopaedics, Osaka University Graduate School of Medicine, Suita; ${ }^{2}$ Department of Orthopaedic Surgery, Osaka Medical Center for Cancer and Cardiovascular Diseases, Osaka; ${ }^{3}$ Department of Orthopaedic Surgery, Osaka National Hospital, Kinki-Block Comprehensive Cancer Center, Osaka; ${ }^{4}$ Medical Center for Translational Research,

Osaka University Hospital, Suita; ${ }^{5}$ Department of Orthopaedic Surgery, Okayama University Graduate

School of Medicine, Dentistry and Pharmaceutical Sciences, Okayama; ${ }^{6}$ Department of Orthopaedic Surgery, Kyoto University Graduate School of Medicine, Kyoto; ${ }^{7}$ Department of Tissue Regeneration, Institute for Frontier Medical Sciences, Kyoto University, Kyoto; ${ }^{8}$ Department of Orthopaedic Surgery, Graduate School of Medical Sciences, Kyushu University, Fukuoka; ${ }^{9}$ Department of Orthopaedic Surgery, Mie University Postgraduate School of Medicine, Tsu; ${ }^{10}$ Department of Orthopaedic Surgery, Osaka City University Graduate School of Medicine, Osaka; ${ }^{11}$ Department of Orthopaedic Surgery, Sapporo Medical University School of Medicine, Sapporo; ${ }^{12}$ Department of Orthopaedic Surgery, Osaka Medical College, Takatsuki;

${ }^{13}$ Department of Orthopaedic Surgery, Himeji Red Cross Hospital, Himeji, Japan
\end{abstract}

Received September 28, 2007; Accepted November 2, 2007

\begin{abstract}
The prognostic implication of SYT-SSX fusion type in synovial sarcomas is still controversial. The aim of this study is to clarify the prognostic impact of fusion type, in association with other clinical factors, in patients with synovial sarcoma in Japan. Data on 108 SYT-SSX fusion transcriptpositive patients with synovial sarcoma, treated in 11 tertiary referral cancer centers in Japan, were retrospectively analyzed. The following parameters were examined for their potential prognostic impact: SYT-SSX fusion type, patient age at presentation, sex, primary tumor location, tumor size, histological subtype, histological grade, treatment modalities and disease stage at presentation. Among the patients with localized disease at presentation, 5-year overall survival (OS) for SYTSSX1 and -2 subgroups were 84.4 and $74.9 \%$, respectively $(\mathrm{P}=0.244)$. Five-year metastasis-free survival (MFS) rates
\end{abstract}

Correspondence to: Dr Takafumi Ueda, Department of Orthopaedic Surgery, Osaka National Hospital, Kinki-Block Comprehensive Cancer Center, 2-1-14 Hoenzaka, Chuo-ku, Osaka 540-0006, Japan

E-mail: uedat@onh.go.jp

Key words: synovial sarcoma, fusion gene, prognostic factor, SYT-SSX were $67.8 \%$ for SYT-SSX1 and $68.5 \%$ for SYT-SSX2 (P=0.949). Univariate survival analyses for 91 patients with localized disease at presentation showed that tumor size was the only significant prognostic factor for OS $(\mathrm{P}=0.0033)$ and MFS $(\mathrm{P}=0.0029)$ and the histological grade was marginally significant for MFS $(\mathrm{P}=0.0785)$, whereas the SYT-SSX fusion type and other variables were not. Multivariate survival analyses further indicated that tumor size was the most significant independent prognostic factor for OS and MFS and the histological grade was also significant for MFS. In conclusion, the SYT-SSX fusion type is not a significant prognostic factor unlike tumor size, followed by histological grade for patients with localized synovial sarcoma in Japan.

\section{Introduction}

Synovial sarcoma is a relatively aggressive soft-tissue sarcoma that accounts for 5 to $10 \%$ of all soft-tissue sarcomas and mainly affects adolescents and young adults (1). Synovial sarcomas are histologically divided into three subtypes: a biphasic subtype containing both epithelial and spindle tumor cells, a monophasic subtype composed solely of spindle tumor cells and a poorly differentiated subtype composed of primitive oval or short-spindle-shaped tumor cells (2). Cytogenetically, however, $>95 \%$ of synovial sarcomas bear the translocation $\mathrm{t}(\mathrm{X} ; 18)(\mathrm{p} 11.2 ; \mathrm{q} 11.2)$, which is a chromosomal re-arrangement specific to this tumor (3). The translocation represents the fusion of the SYT gene on the 18q11.2 chromosome with the 
SSX1 or -2 gene, both of which are closely located on chromosome Xp11.2. The precise function of this chimeric gene still remains unknown, though it has recently been used as a specific diagnostic marker for this tumor (4).

As well as its diagnostic significance, the fusion type has recently been proposed to be a prognostic factor. Kawai et al (5) and subsequently Ladanyi et al (6) reported that the $S Y T$-SSX1 form of synovial sarcoma, compared to that of $S Y T-S S X 2$, has a significantly unfavorable prognosis. Thereafter, several reports with a relatively small number of case series have supported the positive prognostic implication of SYT-SSX fusion type in patients with synovial sarcoma (7-9). In contrast, Guillou et al most recently showed a trend for tumors bearing $S Y T$-SSX2 transcripts to behave more aggressively than those of $S Y T-S S X 1$, but the difference was not statistically significant (10). Thus, the prognostic implication of the SYT-SSX fusion type in synovial sarcomas is still controversial. To address this issue, we conducted the present study to investigate the prognostic impact of the fusion type, in association with other clinical factors, in patients with synovial sarcoma in Japan.

\section{Patients and methods}

As a multi-institutional retrospective study, 108 patients with SYT-SSX-positive synovial sarcoma treated in 11 tertiary referral cancer centers or university hospitals in Japan from 1978 to 2005 were enrolled. All patients were histologically diagnosed as having synovial sarcoma on routine hematoxylin and eosin stains with appropriate immunohistochemical examinations, including a set of epithelial markers such as cytokeratins and epithelial membrane antigen (EMA) in each center, and were confirmed with the detection of SYT-SSX fusion transcripts using the RT-PCR method in frozen tumor samples. We have retrospectively collected patient data from their clinical records including the data on the SYT-SSX fusion type, patient age at presentation, sex, primary tumor location, tumor size, histological subtype, histological grade, treatment modalities and disease stage (presence or absence of metastasis) at presentation. Extremity tumors were defined as tumors located in free extremities only, but extremity girdles including the shoulder, axilla, groin or buttock were considered to be trunk locations. Tumor size was defined as the maximum dimension on a magnetic resonance imaging (MRI) or computed tomography (CT) scan. Histological subtyping was carried out on routine hematoxylin and eosin stains using the 2002 WHO classification of tumors (11). Histological grading was based on the criteria of Enzinger and Weiss and assigned to three grades (1, 2 and 3 ), using several essential histopathological parameters such as cellularity, mitotic activity, tumor necrosis, with or without $\mathrm{Ki}-67$ reactivity as a reliable cell proliferation index (12-16). All patients were treated by the multimodality therapeutic approach, combined with surgery, chemotherapy and/or radiotherapy. Wide local excision for the primary tumors was generally attempted as much as complete re-section was considered possible. Consequently, 63 out of 108 patients underwent wide local excision, 13 patients received marginal excision, 9 intralesional excision, 4 local tumor re-section with an undetermined surgical margin and 15 amputation of the affected limb. The other 4 patients with metastatic disease did not undergo definitive surgery for the primary tumors. Chemotherapy was performed in 83 out of 108 patients (76.9\%), 68 of whom had localized disease and 15 metastatic disease at presentation. The regimens of chemotherapy varied in each center, but mainly included ifosfamide and/or doxorubicin with the exception of 3 cases. Radiotherapy was performed in 23 patients $(21.3 \%)$ pre- and/ or postoperatively with a mean dose of 43.8 Gy (range: $28-70$ Gy). The decision to give adjuvant therapy (chemotherapy and/or radiotherapy) was made independently by each center.

Fusion type analysis. The frozen tumor samples were mostly obtained from the primary site (79 cases), but in some cases from locally recurrent (14 cases) or metastatic sites (3 cases). The other 12 samples were obtained from unspecified tumor sites. Almost all patients were analyzed for the SYT-SSX fusion type by reverse transcription-polymerase chain reaction (RT-PCR) using the SYT primer: 5'-caacagcaagatgcatacca-3', the SSX1 specific primers: 5'-ggtgcagttgtttcccatcg-3' and the SSX2 specific primers: 5'-ggcacagctctttcccatca-3' in most cases, but in some cases using the SSX common primer: 5 '-cacttgct atgcacctgatg-3', followed by direct sequencing.

Statistical analysis. For statistical analysis, the following variables were potentially considered for their prognostic factors: patient age at presentation, sex, primary tumor location, tumor size, histological subtype, histological grade, treatment modalities, disease stage at presentation and fusion type. The correlations between these factors were analyzed using the Pearson $\chi^{2}$ test. Overall survival (OS) was defined as the time from the beginning of treatment to the death of the patient. Metastasis-free survival (MFS) was defined as the first metastasis interval from the beginning of treatment. Patients who died from unrelated causes to sarcoma were censored at the time of death. OS and MFS curves were computed by the Kaplan and Meier method (17). We compared these curves by using the log-rank test (18) for univariate survival analysis. Two-tailed P-values of $\leq 0.05$ were estimated as statistically significant for the prognostic factors. Cox's proportional hazards model was used to identify independent factors predictive of survival for multivariate analysis (19). Patient age at presentation was also evaluated as a continuous variable by Cox's regression model. These statistical analyses were performed using the JMP version 5.01 statistical analysis software package for personal computers (SAS Institute Inc, Cary, NC, USA).

\section{Results}

Patient and tumor characteristics. The patient and tumor characteristics are summarized in Table I. SYT-SSX1 and -2 fusion transcripts were detected in $68(63.0 \%)$ and $40(37.0 \%)$ cases, respectively. There were 44 men (40.7\%) and 64 women. The median age at presentation was 37 (mean, 33 years), ranging from 8 to 74 years. Forty-seven patients $(43.5 \%)$ were aged $\leq 30$. Seventy-two extremity-based tumors included lower $(n=61)$ and upper extremities $(n=11)$. Thirty-six truncal tumors included lower-extremity $(n=17)$ and upperextremity girdles $(n=5)$, head and neck $(n=2)$ and abdominal wall $(n=12)$. The data on maximal tumor size were available 
Table I. Patient and tumor characteristics.

\begin{tabular}{|c|c|c|c|c|}
\hline & \multicolumn{2}{|c|}{ All patients $(n=108)$} & \multicolumn{2}{|c|}{$\begin{array}{l}\text { Patients with localized disease at } \\
\text { presentation }(n=91)\end{array}$} \\
\hline & $\mathrm{N}$ & $\%$ & $\mathrm{~N}$ & $\%$ \\
\hline \multicolumn{5}{|l|}{ Fusion type } \\
\hline$S Y T-S S X 1$ & 68 & 63.0 & 57 & 62.6 \\
\hline$S Y T-S S X 2$ & 40 & 37.0 & 34 & 37.4 \\
\hline \multicolumn{5}{|l|}{ Age } \\
\hline$\leq 30$ & 47 & 43.5 & 40 & 44.0 \\
\hline$>30$ & 61 & 56.5 & 51 & 56.0 \\
\hline$\leq 35$ & 55 & 50.9 & 45 & 49.5 \\
\hline$>35$ & 53 & 49.1 & 46 & 50.5 \\
\hline \multicolumn{5}{|l|}{ Sex } \\
\hline Male & 44 & 40.7 & 33 & 36.3 \\
\hline Female & 64 & 59.3 & 58 & 63.7 \\
\hline \multicolumn{5}{|l|}{ Location } \\
\hline Extremity & 72 & 66.7 & 60 & 65.9 \\
\hline Trunk & 36 & 33.3 & 31 & 34.1 \\
\hline \multicolumn{5}{|c|}{ Tumor size (9 unspecified) } \\
\hline$\leq 5 \mathrm{~cm}$ & 35 & 35.4 & 33 & 39.8 \\
\hline$>5 \mathrm{~cm}$ & 64 & 64.6 & 50 & 60.2 \\
\hline$\leq 7 \mathrm{~cm}$ & 44 & 44.4 & 42 & 50.6 \\
\hline$>7 \mathrm{~cm}$ & 55 & 55.6 & 41 & 49.4 \\
\hline \multicolumn{5}{|c|}{ Histological subtype (1 unspecified) } \\
\hline Poorly differentiated & 8 & 7.5 & 4 & 4.4 \\
\hline Monophasic & 67 & 62.6 & 58 & 64.4 \\
\hline Biphasic & 32 & 29.9 & 28 & 31.1 \\
\hline \multicolumn{5}{|c|}{ Histological grade (22 unspecified) } \\
\hline Grade 2 & 48 & 55.8 & 44 & 61.1 \\
\hline Grade 3 & 38 & 44.2 & 28 & 38.9 \\
\hline \multicolumn{5}{|l|}{ Stage } \\
\hline Localized & 91 & 84.3 & 91 & 100 \\
\hline Metastatic & 17 & 15.7 & & \\
\hline \multicolumn{5}{|c|}{ Surgery (4 unspecified and 4 no surgery) } \\
\hline Amputation & 15 & 15.0 & 11 & 12.8 \\
\hline Wide local excision & 63 & 63.0 & 56 & 65.1 \\
\hline Marginal excision & 13 & 13.0 & 12 & 14.0 \\
\hline Intralesional excision & 9 & 9.0 & 7 & 8.1 \\
\hline \multicolumn{5}{|l|}{ Chemotherapy } \\
\hline No & 25 & 23.1 & 23 & 25.3 \\
\hline Yes & 83 & 76.9 & 68 & 74.7 \\
\hline \multicolumn{5}{|l|}{ Radiotherapy } \\
\hline No & 85 & 78.7 & 72 & 79.1 \\
\hline Yes & 23 & 21.3 & 19 & 20.9 \\
\hline
\end{tabular}




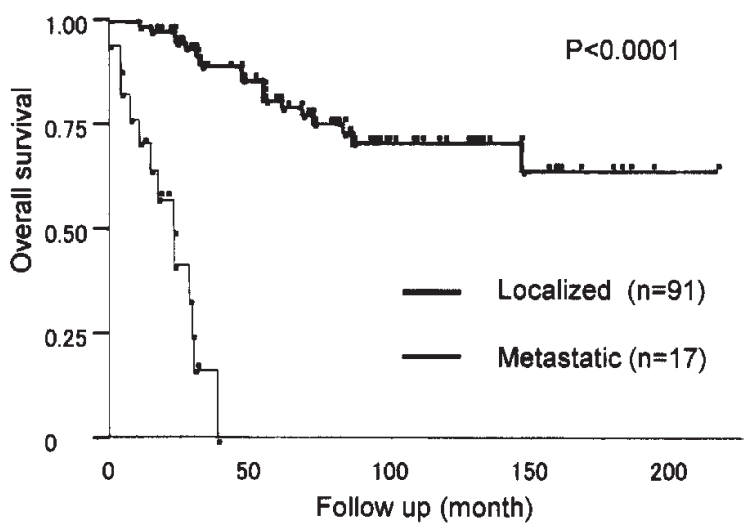

Figure 1. Overall survival according to the disease stage in all patients.

in 99 cases. The tumor was $<5 \mathrm{~cm}$ in 35 patients $(35.4 \%)$, between 5 and $7 \mathrm{~cm}$ in 9 patients $(9.0 \%)$ and $>7 \mathrm{~cm}$ in 55 patients $(55.6 \%)$. The histological subtype was specified in all but one case. The most frequent histological subtype was the monophasic fibrous $(n=67,62.6 \%)$, followed by the biphasic $(\mathrm{n}=32,29.9 \%)$ and poorly differentiated subtype $(\mathrm{n}=8,7.5 \%)$. The histological grade was determined in 86 cases, grade 2 in 48 and grade 3 in 38 cases. The initial treatment modalities for 108 patients included surgery alone $(n=23,21.3 \%)$; a combination of surgery and radiotherapy $(n=2,1.9 \%)$; a combination of surgery and chemotherapy $(\mathrm{n}=59,54.3 \%)$; a combination of surgery, radiotherapy and chemo-therapy $(\mathrm{n}=20,18.5 \%)$; a combination of radiotherapy and chemotherapy $(\mathrm{n}=1,0.9 \%)$ and chemotherapy alone $(n=3,2.8 \%)$. Ninety-one patients $(84.3 \%)$ had localized disease and 17 patients $(15.7 \%)$ had metastasis at presentation. Follow-up periods ranged from 4 to 216 months (median, 54 and mean, 64 months).

Correlations between the various factors. The correlations between the SYT-SSX fusion type and other clinical factors are listed in Table II. A significant correlation between the fusion type and primary tumor location was observed $(\mathrm{P}=0.0166)$, suggesting a preponderance of truncal (more proximal) tumor location in SYT-SSX2 fusion type than in SYT-SSX1. There was also a trend for patients with SYT-SSX2 tumors to have a more monophasic fibrous histological subtype, including a poorly differentiated subtype, than those with SYT-SSXI tumors. However, the difference did not reach statistical significance in the present series ( 80 vs $64.2 \%, \mathrm{P}=0.0837$ ). There was no correlation of the fusion type with patient age, sex, tumor size, histological grade, disease stage and treatment modalities including surgery, chemotherapy and radiotherapy.

As for the associations between the disease stage and other factors, the number of patients with metastasis at presentation was significantly smaller in females $(\mathrm{P}=0.0297)$, with smaller tumors $(<5$ vs $>5 \mathrm{~cm}$ : $\mathrm{P}=0.0368$ or $<7$ vs $>7 \mathrm{~cm}: \mathrm{P}=0.0050)$, and histological grade 2 tumors $(\mathrm{P}=0.0249)$, but the SYT-SSX fusion type, patient age, primary tumor location or histological subtype did not significantly associate with the disease stage at presentation.

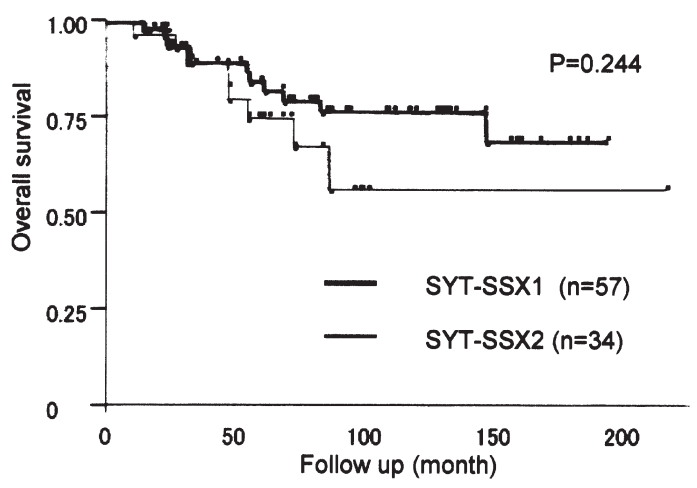

Figure 2. Overall survival according to the fusion type in patients with localized disease at presentation.

The survival analysis and prognostic factors of all patients. Thirty-two patients $(29.6 \%)$ died of their tumors, including $13(76.5 \%)$ out of 17 patients with metastasis at presentation Five-year overall survival (OS) was $69.8 \%$ in all patients. The results of the univariate analysis for predictors of OS in all patients are summarized in Table III. Male patients $(\mathrm{P}=0.0290)$, with tumor sizes $>5 \mathrm{~cm}(\mathrm{P}=0.0051)$ or $>7 \mathrm{~cm}$ $(\mathrm{P}=0.0003)$, histological grade $3(\mathrm{P}=0.0265)$ and a presence of metastasis at presentation $(\mathrm{P}<0.0001)$ (Fig. 1) were significantly unfavorable predictors of OS in all patients. The fusion type, patient age, primary tumor location and histological subtype showed no prognostic impact on the OS in any of the patients. Then, we performed a multivariate survival analysis including fusion type in 81 patients, whose information about the four prognostic factors in univariate survival analysis (sex, tumor size, histological grade and disease stage) was available (Table IV). It showed that the disease stage at presentation was the most important independent predictor for OS $(\mathrm{P}<0.001)$, followed by tumor size $(\mathrm{P}=0.021)$. However, fusion type, sex and histological grade were not independent prognostic factors in the multivariate analysis for OS in all patients.

Survival analysis and prognostic factors: patients with localized disease at presentation. Among the 91 patients with localized disease at presentation, 28 patients $(30.8 \%)$ developed at least one metastasis and 31 patients $(34.1 \%)$ developed a local recurrence in the course of their disease. Five-year OS and MFS were 81.1 and $67.9 \%$, respectively, in patients with localized disease at presentation. Univariate analyses for predictors of OS and MFS in patients with localized disease at presentation are shown in Table III SYT-SSX2 tumors tended to behave in a more aggressive manner than SYT-SSXI tumors on OS, but the difference was not statistically significant $(\mathrm{P}=0.244)$ (Fig. 2). Tumor size was significantly associated with $\mathrm{OS}(5 \mathrm{~cm}, \mathrm{P}=0.0233 ; 7 \mathrm{~cm}$, $\mathrm{P}=0.0033)$ (Fig. 3a and b) and MFS ( $5 \mathrm{~cm}, \mathrm{P}=0.0127 ; 7 \mathrm{~cm}$, $\mathrm{P}=0.0029$ ) (Fig. 4a and b). The histological grade also marginally correlated with OS $(\mathrm{P}=0.156)$ and MFS $(\mathrm{P}=0.0785)$ (Fig. 5), but it did not reach statistical significance in the present series. Patient age, sex, primary tumor location and the histological subtype did not correlate with either OS or MFS. 
Table II. Correlations between the SYT-SSX fusion type and other factors.

\begin{tabular}{|c|c|c|c|}
\hline & SYT-SSX1 (n=68) & SYT-SSX2 (n=40) & $\mathrm{P}$ \\
\hline \multicolumn{4}{|l|}{ Age } \\
\hline$\leq 30$ & 27 & 20 & \multirow[t]{2}{*}{0.297} \\
\hline$>30$ & 41 & 20 & \\
\hline$\leq 35$ & 33 & 22 & \multirow[t]{2}{*}{0.516} \\
\hline$>35$ & 35 & 18 & \\
\hline \multicolumn{4}{|l|}{ Sex } \\
\hline Male & 31 & 13 & \multirow[t]{2}{*}{0.181} \\
\hline Female & 37 & 27 & \\
\hline \multicolumn{4}{|l|}{ Location } \\
\hline Extremity & 51 & 21 & \multirow[t]{2}{*}{0.0166} \\
\hline Trunk & 17 & 19 & \\
\hline \multicolumn{4}{|l|}{ Tumor size } \\
\hline$\leq 5 \mathrm{~cm}$ & 24 & 11 & \multirow[t]{2}{*}{0.363} \\
\hline$>5 \mathrm{~cm}$ & 38 & 26 & \\
\hline$\leq 7 \mathrm{~cm}$ & 27 & 17 & \multirow[t]{2}{*}{0.816} \\
\hline$>7 \mathrm{~cm}$ & 35 & 20 & \\
\hline \multicolumn{4}{|l|}{ Histological subtype } \\
\hline Poorly differentiated monophasic & 43 & 32 & \multirow[t]{2}{*}{0.0837} \\
\hline Biphasic & 24 & 8 & \\
\hline \multicolumn{4}{|l|}{ Historical grade } \\
\hline Grade 2 & 32 & 16 & \multirow[t]{2}{*}{0.280} \\
\hline Grade 3 & 21 & 17 & \\
\hline \multicolumn{4}{|l|}{ Stage } \\
\hline Localized & 57 & 34 & \multirow[t]{2}{*}{0.871} \\
\hline Metastatic & 11 & 6 & \\
\hline \multicolumn{4}{|l|}{ Surgery } \\
\hline Amputation and wide local excisions & 48 & 30 & \multirow[t]{2}{*}{$0.835^{\mathrm{a}}$} \\
\hline Marginal and intralesional excisions & 13 & 9 & \\
\hline \multicolumn{4}{|l|}{ Chemotherapy } \\
\hline No & 15 & 10 & \multirow[t]{2}{*}{0.726} \\
\hline Yes & 53 & 30 & \\
\hline \multicolumn{4}{|l|}{ Radiotherapy } \\
\hline No & 54 & 31 & \multirow[t]{2}{*}{0.815} \\
\hline Yes & 14 & 9 & \\
\hline
\end{tabular}

${ }^{a}$ The amputation and wide local excisions were categorized as adequate surgery. The marginal and intralesional excisions were categorized as inadequate surgery. The numbers of the two groups were compared using the Pearson $\chi^{2}$ test.

Multivariate analyses for OS and MFS were then applied to 67 localized patients, whose information on all the factors was available and we took the tumor size, histological grade and fusion type into account. Tumor size ( $<7 \mathrm{vs}>7 \mathrm{~cm})$ was the only independent prognostic factor on both OS $(\mathrm{P}=0.009)$ and MFS $(\mathrm{P}=0.024)$. Moreover, the histological grade proved to be an independent prognostic factor on MFS $(\mathrm{P}=0.037)$ (Table V). The fusion type did not have a prognostic impact on either OS or MFS. 
Table III. Survival according to various factors in all of the patients $(\mathrm{n}=108)$ and patients with localized disease at presentation $(\mathrm{n}=91)$.

\begin{tabular}{|c|c|c|c|c|c|c|c|}
\hline \multicolumn{3}{|c|}{ All patients $(n=108)$} & \multicolumn{5}{|c|}{ Patients with localized disease at presentation $(n=91)$} \\
\hline $\mathrm{N}$ & $\begin{array}{l}\text { 5-year } \\
\text { OS rate }\end{array}$ & $\mathrm{P}$ & $\mathrm{N}$ & $\begin{array}{l}\text { 5-year } \\
\text { OS rate }\end{array}$ & $\mathrm{P}$ & $\begin{array}{c}\text { 5-year } \\
\text { MFS rate }\end{array}$ & $\mathrm{P}$ \\
\hline
\end{tabular}

\begin{tabular}{|c|c|c|c|c|c|c|c|c|}
\hline \multicolumn{9}{|l|}{ Fusion type } \\
\hline$S Y T-S S X 1$ & 68 & 71.1 & 0.5320 & 57 & 84.4 & 0.2440 & 67.8 & 0.9490 \\
\hline$S Y T-S S X 2$ & 40 & 66.8 & & 34 & 74.9 & & 68.5 & \\
\hline \multicolumn{9}{|l|}{ Age } \\
\hline$\leq 30$ & 47 & 68.7 & 0.4160 & 40 & 77.5 & 0.5070 & 70.0 & 0.7770 \\
\hline$>30$ & 61 & 68.7 & & 51 & 81.3 & & 65.4 & \\
\hline$\leq 35$ & 55 & 67.7 & 0.4320 & 45 & 80.6 & 0.1500 & 71.2 & 0.3680 \\
\hline$>35$ & 53 & 68.7 & & 46 & 78.3 & & 63.4 & \\
\hline \multicolumn{9}{|l|}{ Sex } \\
\hline Male & 44 & 67.7 & 0.0290 & 33 & 79.6 & 0.6470 & 68.0 & 0.8730 \\
\hline Female & 64 & 72.6 & & 58 & 82.2 & & 67.9 & \\
\hline \multicolumn{9}{|l|}{ Location } \\
\hline Extremity & 72 & 57.4 & 0.8390 & 60 & 82.0 & 0.5680 & 72.2 & 0.1730 \\
\hline Trunk & 36 & 78.1 & & 31 & 76.6 & & 61.9 & \\
\hline \multicolumn{9}{|l|}{ Tumor size } \\
\hline$\leq 5 \mathrm{~cm}$ & 35 & 85.0 & 0.0051 & 33 & 91.3 & 0.0233 & 79.4 & 0.0127 \\
\hline$>5 \mathrm{~cm}$ & 64 & 57.5 & & 50 & 70.4 & & 56.9 & \\
\hline$\leq 7 \mathrm{~cm}$ & 44 & 82.2 & 0.0003 & 42 & 86.7 & 0.0033 & 82.0 & 0.0029 \\
\hline$>7 \mathrm{~cm}$ & 55 & 54.5 & & 41 & 69.9 & & 48.7 & \\
\hline \multicolumn{9}{|l|}{ Histological subtype } \\
\hline Poorly differentiated & 8 & $\mathrm{~N} / \mathrm{A}$ & & 4 & N/A & & N/A & \\
\hline Monophasic & 67 & 70.4 & 0.3690 & 58 & 81.5 & 0.3330 & 66.2 & 0.2710 \\
\hline Biphasic & 32 & 67.9 & & 28 & 79.0 & & 71.3 & \\
\hline \multicolumn{9}{|l|}{ Histological grade } \\
\hline Grade 2 & 48 & 77.8 & 0.0265 & 44 & 86.5 & 0.1560 & 67.4 & 0.0785 \\
\hline Grade 3 & 38 & 52.1 & & 28 & 68.6 & & 53.4 & \\
\hline \multicolumn{9}{|l|}{ Stage } \\
\hline Localized & 91 & 81.1 & $<0.00010$ & 91 & 81.1 & & 67.9 & \\
\hline Metastatic & 17 & 0.00 & & & & & & \\
\hline
\end{tabular}

N/A, not available.

\section{Discussion}

In synovial sarcoma, there are several definite adverse clinical prognostic factors consistently reported in a previous large series: the advanced disease stage, large tumor size and presence of local recurrence (20-29). An adjacent bone and/ or neurovascular invasion $(24,25,27)$ and a microscopic positive tumor margin $(22,24)$ also reflect on the failure of the local control associated with a poor prognosis. As for other clinical prognostic factors in patients with localized synovial sarcoma, older age $(21,23,26)$, male sex $(25)$, truncal/proximal tumor location $(21,25,29)$ and a high histological grade
$(10,25,29)$ are identified as significant adverse predictors for survival in several of the series. The present study has reconfirmed a strong association of the presence of metastasis at presentation with a worse OS $(\mathrm{P}<0.0001)$ in all patients and of a large tumor size with a significantly worse OS $(>5 \mathrm{~cm}$, $\mathrm{P}=0.0233 ;>7 \mathrm{~cm}, \mathrm{P}=0.0033)$ and $\operatorname{MFS}(>5 \mathrm{~cm}, \mathrm{P}=0.0127$; $>7 \mathrm{~cm}, \mathrm{P}=0.0029)$ in patients with localized disease at presentation. Primary tumor size is an established prognostic factor in not only synovial sarcoma but also in other softtissue sarcomas (30-32) and has been adopted as one of the essential parameters for the AJCC/UICC clinical staging system in soft-tissue sarcomas, together with tumor depth, 
a

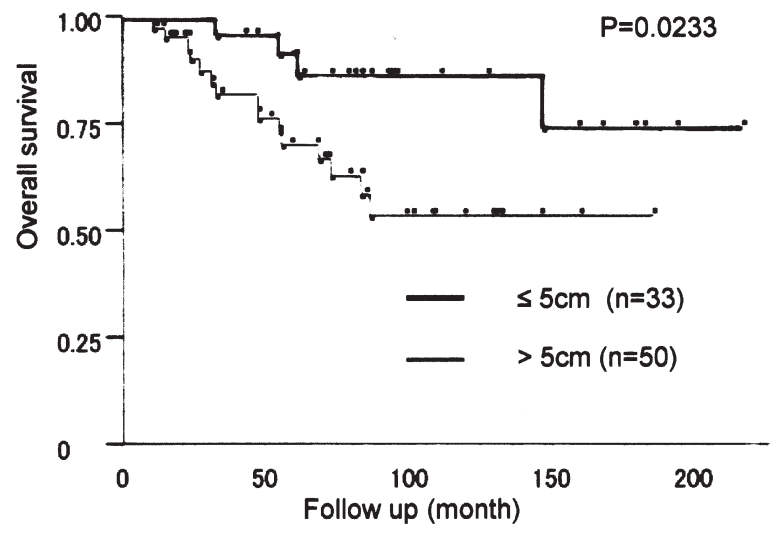

b

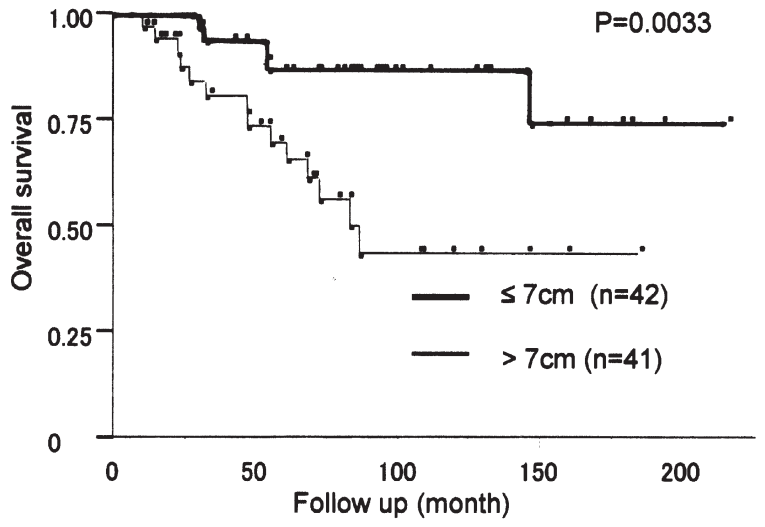

Figure 3. Overall survival according to tumor size (a) $>5$ or $<5 \mathrm{~cm}$, (b) $>7$ or $<7 \mathrm{~cm}$, in patients with localized disease at presentation.

$\mathbf{a}$

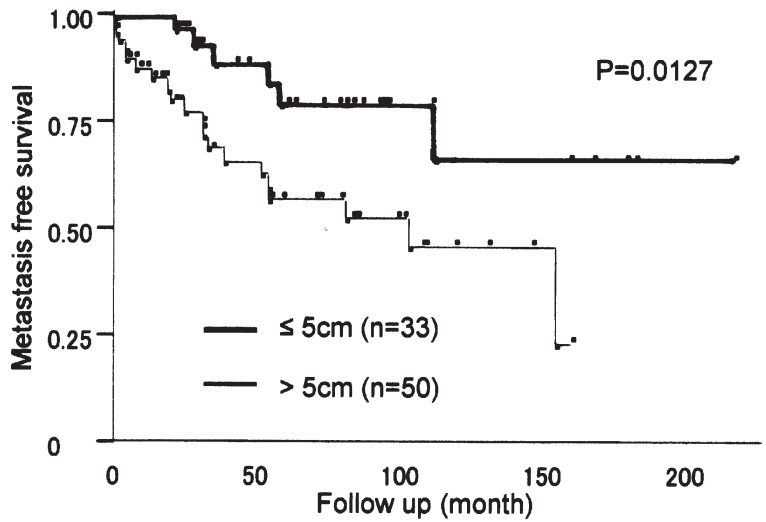

b

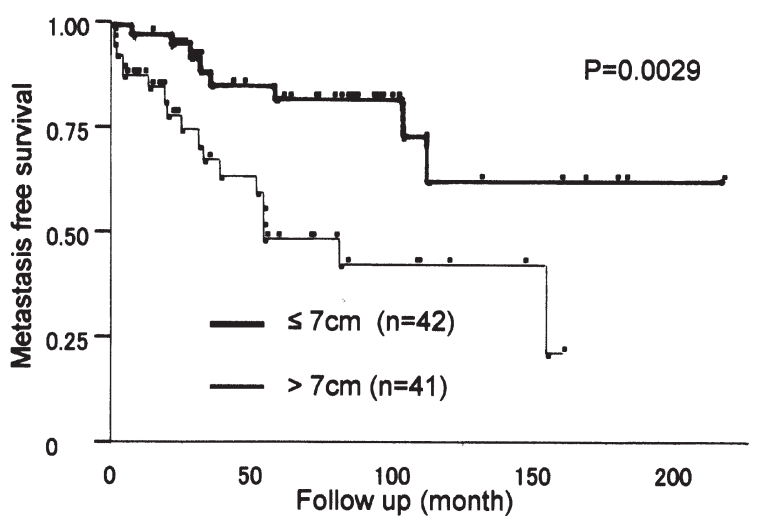

Figure 4. Metastasis-free survival according to tumor size (a) $>5$ or $<5 \mathrm{~cm}$, (b) $>7$ or $<7 \mathrm{~cm}$, in patients with localized disease at presentation.

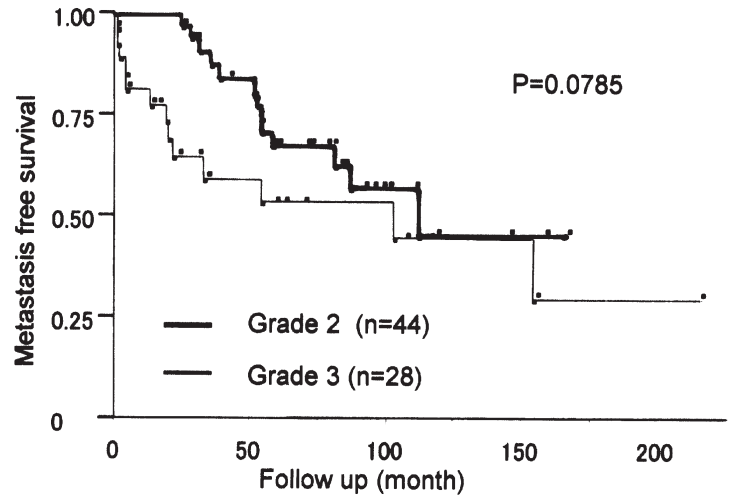

Figure 5. Metastasis-free survival according to the histological grade in patients with localized disease at presentation.

histological grade and the status of regional lymph nodes/ distant metastases (33).

Guillou et al (10) recently demonstrated that the French Federation of Cancer Centers (FNCLCC) histological grade (grade 2 vs 3 ) is the most important prognostic factor for survival in patients with synovial sarcoma. In the present study, the histological grade proved to be an independent prognostic factor for MFS in a multivariate analysis on patients with localized disease at presentation $(\mathrm{P}=0.037)$, following tumor size $(\mathrm{P}=0.024)$, though not independently on OS. Among the histopathological factors, a poorly differentiated histology $(10,23,34)$, tumor necrosis $(10,21,23,25,34)$, high mitotic activity $(8,10,21,22,25,34)$ and a high Ki67 (MIB-1) proliferation index $(8,34,35)$ have also been associated with the prognosis of patients with synovial sarcoma and all of these histopathological factors are considered to contribute to the histological grade.

In the present study, female patients showed significantly better OS in the univariate analysis for all patients probably because the number of female patients who had metastasis at presentation was considerably fewer than that of the male ones. This survival difference according to sex lost its prognostic value for patients with localized disease at presentation. From the previous series, Trassard et al (25), from the FNCLCC Sarcoma Group, has reported the male sex as an adverse prognostic factor in patients with localized primary synovial sarcoma. The reason why the number of female patients with metastasis at presentation was fewer than the males in the present series could not be explained.

Several studies have reported the clinical difference according to the fusion type (5-10). The association of the fusion type with prognosis in synovial sarcoma patients was first reported by Kawai et al (5) in 1998 in a preliminary series of 45 patients. They postulated that patients with SYT-SSX1 bearing synovial sarcoma showed a poorer prognosis than 
Table IV. Multivariate analysis for overall survival according to the various factors in all patients $(n=81)$.

\begin{tabular}{lcl} 
& \multicolumn{3}{c}{ OS (all patients $\mathrm{n}=81)$} \\
\hline $\begin{array}{l}\text { Risk } \\
\text { ratio }\end{array}$ & $95 \% \mathrm{Cl}$ & $\mathrm{P}$
\end{tabular}

\section{Fusion type}

$$
\text { SYT-SSX1 }
$$

$0.64-3.28$

Sex

$$
\text { Male }
$$

Tumor size

$$
\leq 7 \mathrm{~cm}
$$

$1.17-8.80$

Histological grade

Grade 2

$$
1.27 \quad 0.55-2.97
$$

Stage

\begin{tabular}{llll} 
Localized & 9.77 & $3.31-32.6$ & $<0.001$ \\
\hline
\end{tabular}

those with the SYT-SSX2 fusion type. This hypothesis was supported by several other series of relatively small numbers of patients (7-9,36) and Ladanyi et al (6) confirmed it in 2002 by conducting a multi-institutional retrospective analysis in 243 patients. In contrast, Guillou et al (10) reported a large series of 165 patients with synovial sarcoma, in which there was a trend for tumors bearing SYT-SSX2 to behave more aggressively than $S Y T$-SSX1, though the difference was not statistically significant. Our preliminary study, including 10 patients with synovial sarcoma, also showed that all tumors expressing $S Y T-S S X 2(\mathrm{n}=3)$ had a recurrence, suggesting that SYT-SSX2 may correlate with an aggressive character as compared with SYT-SSXI (37). Thus, the issue of prognostic implication of the fusion type in synovial sarcoma is still controversial. In our present study, SYT-SSX2 tumors tended to behave in a more aggressive manner than SYT-SSXI (Fig. 2), but the difference did not reach statistical significance
( $\mathrm{P}=0.244)$, concordant with the results reported by Guillou et al (10). The patient and tumor characteristics in our present series are nearly comparable to other major series $(6,10,24-26,28)$, thus the relative lack of prognostic impact of the fusion type cannot be attributed to these selection biases. The treatment strategy is also basically equivalent, except for the relatively more frequent application of adjuvant chemotherapy in our present series $(83 / 108$ patients, $76.9 \%)$ compared with other series [38\% (24), $41 \%$ (28), $44 \%$ (38), 53\% (26), 57\% (10), $62 \%(6)]$.

Previous representative large series of adult synovial sarcoma have shown 5-year OS from 57 to $75 \%$ (24-26,28). The 5-year OS of the patients with localized disease at presentation in the present series was $81.1 \%$. This relatively better result may be attributed to the high application rate of adjuvant chemotherapy, though we did not show a significant difference in survival between patients treated with and those without adjuvant chemotherapy, probably because of the diversity of chemotherapeutic regimens in each center. Brecht et al (39) suggested that the more satisfactory survival in pediatric synovial sarcoma patients (5-year survival: 80$89 \%$ ) than in adults is attributed not only to age itself but also the therapeutic strategy in which pediatric patients generally receive adjuvant chemotherapy regardless of the risk factors. The role of chemotherapy mainly consisting of ifosfamide with or without doxorubicin in adult patients with synovial sarcoma (at least for high-risk cases) has been recognized (40-42). Thus, a high application rate of adjuvant chemotherapy in the present series may lead to a better survival as compared with other major series. Notably, Guetz et al reported at the 2004 ASCO annual meeting that SYT-SSX2 bearing synovial sarcomas appeared to present a better chemosensitivity than SYT-SSX1 $(\mathrm{n}=14, \mathrm{P}=0.09)$, suggesting that chemotherapy overshadows the natural prognosis of patients with synovial sarcoma which is possibly influenced by their fusion type.

In addition to patient prognosis, an association of the fusion type with the histological subtype in synovial sarcoma has already been reported $(43,44)$. We also observed the same trend that tumors bearing SYT-SSX2 rarely show a biphasic pattern, as previously reported, with marginal significance

Table V. Multivariate analysis for survivals according to the various factors in 67 patients with localized disease at presentation.

\section{OS}

(67 patients with localized disease at presentation)

\section{MFS}

(67 patients with localized disease at presentation)

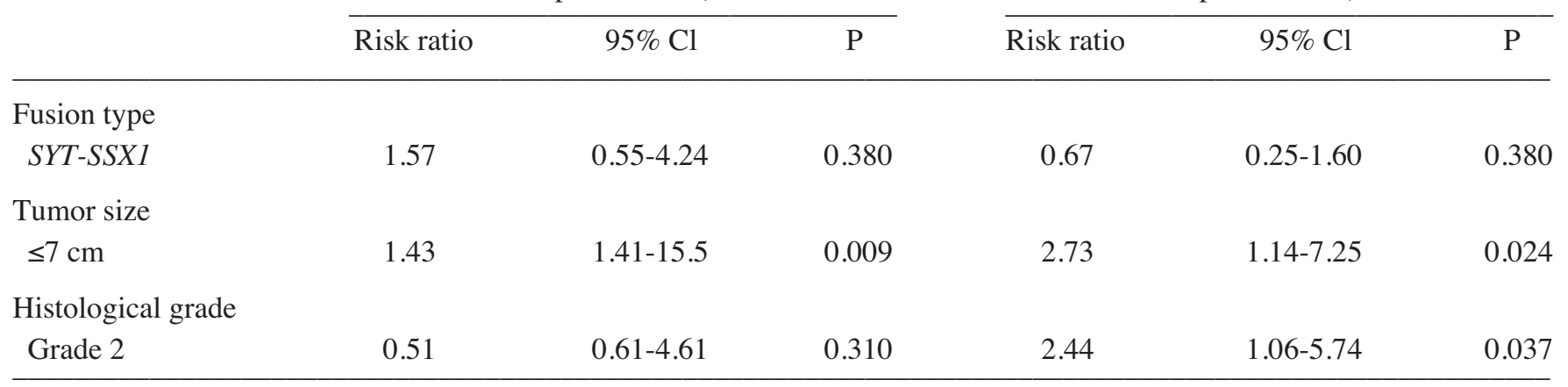


$(\mathrm{P}=0.0837)$. Of note is that we observed a significant association between the fusion type and primary tumor location with a majority of SYT-SSX1 tumors being in the extremities, whereas SYT-SSX2 tumors were equally located in the extremities $(n=21)$ and trunk $(n=19)(P=0.0166)$. This trend was also observed in the series of Ladanyi et al (6) $(\mathrm{P}=0.07)$ and Guillou et al $(10)(\mathrm{P}=0.052)$. It may be hypothesized that a susceptibility of $S S X 1$ and -2 fusion to SYT may vary in different parts of the body.

In conclusion, our present study demonstrates that the $S Y T$-SSX fusion type is not a significant prognostic factor in patients with synovial sarcoma, as Guillou et al (10) reported and that the most significant prognostic factor is tumor size followed by the histological grade in patients with localized synovial sarcoma. We also confirm the association between the fusion type and histological subtype and between the fusion type and primary tumor location. A systematic review by a meta-analysis procedure, or prospective large cohort study may be warranted to finally clarify the true prognostic impact of the SYT-SSX fusion type on the survival of patients with synovial sarcoma perhaps even with a future international collaboration.

\section{Acknowledgements}

This study was supported in part by a Grant-in-Aid for Scientific Research (\#16390439) from the Ministry of Education, Culture, Sports, Science and Technology of Japan. This study was presented in part at the 38th Annual Musculoskeletal Tumor Meeting of the Japanese Orthopaedic Association, July, 2005, at Pacifico Yokohama, Japan.

\section{References}

1. Kransdorf MJ: Malignant soft-tissue tumors in a large referral population: Distribution of diagnoses by age, sex, and location. Am J Roentgenol 164: 129-134, 1995.

2. Enzinger FM and Weiss SW: Synovial Sarcoma. In: Soft-tissue tumors. Enzinger FM and Weiss SW (eds). 3rd edition Mosby, St Louis, pp757-786, 1995.

3. Sandberg AA and Bridge JA: Updates on the cytogenetics and molecular genetics of bone and soft-tissue tumors: Synovial sarcoma. Cancer Genet Cytogenet 133: 1-23, 2002.

4. Guillou L, Coindre J, Gallagher G, et al: Detection of the synovial sarcoma translocation $\mathrm{t}(\mathrm{X} ; 18)(\mathrm{SYT} ; \mathrm{SSX})$ in paraffinembedded tissues using reverse transcriptase-polymerase chain reaction: a reliable and powerful diagnostic tool for pathologists. A molecular analysis of 221 mesenchymal tumors fixed in different fixatives. Hum Pathol 32: 105-112, 2001.

5. Kawai A, Woodruff J, Healey JH, et al: $S Y T-S S X$ gene fusion as a determinant of morphology and prognosis in synovial sarcoma. N Engl J Med 338: 153-160, 1988.

6. Ladanyi M, Antonescu CR, Leung DH, et al: Impact of SYT-SSX fusion type on the clinical behavior of synovial sarcoma: A multiinstitutional retrospective study of 243 patients. Cancer Res 62: 135-140, 2002.

7. Nilsson G, Skytting B, Xie Y, et al: The SYT-SSX1 variant of synovial sarcoma is associated with a high rate of tumor cell proliferation and poor clinical outcome. Cancer Res 59: 3180-3184, 1999.

8. Inagaki H, Nagasaka T, Otsuka T, et al: Association of SYT-SSX fusion types with proliferative activity and prognosis in synovial sarcoma. Mod Pathol 13: 482-488, 2000.

9. Mezzelani A, Matiani L, Tamborini E, et al: SYT-SSX fusion genes and prognosis in synovial sarcoma. Br J Cancer 85: 1535-1539, 2001.

10. Guillou L, Benhattar J, Bonichon F, et al: Histologic grade but not $S Y T-S S X$ fusion type, is an important prognostic factor in patients with synovial sarcoma: A multicenter, retrospective analysis. J Clin Oncol 22: 4040-4050, 2004.
11. Fletcher CDM, Unni KK and Mertens F: World Health Organization Classification of Tumours: Pathology and Genetics of Tumours of Soft Tissue and Bone. IARC Press, Lyon, 2002.

12. Weiss SW and Goldblum Jr: General Considerations. In: Enzinger and Weiss's Soft-Tissue Tumors. Goldblum Jr and Weiss SW (eds). 4th edition Mosby, St. Louis, pp6-14, 2001.

13. Ueda T, Aozasa K, Tsujimoto M, et al: Prognostic significance of $\mathrm{Ki}-67$ reacticity in soft-tissue sarcomas. Cancer 63: 1607-1611, 1989.

14. Drobnjak M, Latres E, Pollack D, et al: Prognostic implications of p53 nuclear overexpression and high proliferation index of Ki-67 in adult soft-tissue sarcomas. J Natl Cancer Inst 86: 549-554, 1994.

15. Heslin MJ, Cordon-Cardo C, Lewis JJ, et al: Ki-67 detected by MIB-1 predicts distant metastasis and tumor mortality in primary, high grade extremity soft-tissue sarcoma. Cancer 83 : 490-497, 1998.

16. Hasegawa T, Yamamoto S, Yokoyama R, et al: Prognostic significance of grading and staging systems using MIB-1 score in adult patients with soft-tissue sarcoma of the extremities and trunk. Cancer 95: 843-851, 2002.

17. Kaplan EL and Meier P: Nonparametric estimation from incomplete observations. J Am Stat Assoc 53: 457-481, 1958.

18. Peto R, Pike MC, Armitage, et al: Design and analysis of randomized clinial trials requiring prolonged observation of each patient: Part II analyses and examples. Br J Cancer 35: 1-39, 1977.

19. Cox DR: Regression models and life tables (with discussion). J R Stat Soc B 34: 187-220, 1972.

20. Brodsky JT, Burt ME, Hajdu SI, et al: Tendosynovial sarcoma. Clinicopathologic features, treatment, and prognosis. Cancer 70 : 484-489, 1992.

21. Oda Y, Hashimoto H, Tsuneyoshi M, et al: Survival in synovial sarcoma: A multivariate study of prognostic factors with special emphasis on the comparison between early death and long-term survival. Am J Surg Pathol 17: 35-44, 1933.

22. Singer S, Baldini EH, Demetri GD, et al: Synovial sarcoma: Prognostic significance of tumor size, margin of resection, and mitotic activity for survival. J Clin Oncol 14: 1201-1208, 1996.

23. Bergh P, Meis-Kindblom JM, Gherlinzoni F, et al: Synovial sarcoma. Identification of low and high risk groups. Cancer 85: 2596-2607, 1999.

24. Lewis JJ, Antonescu CR, Leung DH, et al: Synovial sarcoma: A multivariate analysis of prognostic factors in 112 patients with primary localized tumor of extremity. J Clin Oncol 18: 2087-2094, 2000 .

25. Trassard M, Le Doussal V, Hacène K, et al: Prognostic factors in localized primary synovial sarcoma: A multicenter study of 128 adult patients. J Clin Oncol 19: 525-534, 2001.

26. Spillane AJ, A'Hern R, Judson IR, et al: Synovial sarcoma: A clinicopathologic, staging, and prognostic assessment. J Clin Oncol 18: 3794-3803, 2000.

27. Okcu MF, Munsell M, Treuner J, et al: Synovial sarcoma of childhood and adolescence: a multicenter, multivariate analysis of outcome. J Clin Oncol 21: 1602-1611, 2003.

28. Ferrari A, Gronchi A, Casanova M, et al: Synovial sarcoma: A retrospective analysis of 271 patients of all ages treated at a single institution. Cancer 101: 627-634, 2004.

29. Deshmukh R, Mankin HJ and Singer S: Synovial sarcoma: the importance of size and location for survival. Clin Orthop 419: 155-161, 2004.

30. Ueda T, Aozasa K, Tsujimoto M, et al: Multivariate analysis for clinical prognostic factors in 163 patients with soft-tissue sarcoma. Cancer 62: 1444-1450, 1988.

31. Zagars GK, Mullen JR, Pollack A: Malignant fibrous histiocytoma: outcome and prognostic factors following conservation surgery and radiotherapy. Int J Radiat Oncol Biol Phys 34: 983-994, 1996.

32. Collin CF, Friedrich C, Godbold J, et al: Prognostic factors for local recurrence and survival in patients with localized extremity soft-tissue sarcoma. Semin Surg Oncol 4: 30-37, 1988.

33. International Union Against Cancer. Tumours of bone and soft tissues. In: TNM classification of malignant tumours. Sobin LH and Wittekind C (eds). 6th edition Wiley-Liss, New York, pp114-118, 2002.

34. Hasegawa T, Yokoyama R, Matsuno Y, et al: Prognostic significance of histologic grade and nuclear expression of beta catenin in synovial sarcoma. Hum Pathol 32: 257-263, 2001. 
35. Skytting BT, Bauer HC, Perfekt R, et al: Ki-67 is strongly prognostic in synovial sarcoma: analysis based on 86 patients from the Scandinavian Sarcoma group register. Br J Cancer 80: 1809-1814, 1999.

36. Panagopoulos I, Mertens F, Isaksson M, et al: Clinical impact of molecular and cytogenetic findings in synovial sarcoma. Genes Chromosomes Cancer 31: 363-372, 2001

37. Hashimoto N, Araki N, Fukuda H, et al: Clinical relevance of the SYT-SSX fusion gene in synovial sarcoma. J Musculoskel Res 1: 111-119, 1997.

38. Cagle LA, Mirra JM, Storm K, et al: Histologic features relating to prognosis in synovial sarcoma. Cancer 59: 18101814, 1987.

39. Brecht IB, Ferrari A, Int-Veen C, et al: Grossly-resected synovial sarcoma treated by the German and Italian pediatric soft-tissue sarcoma cooperative groups: discussion on the role of adjuvant therapies. Pediatr Blood Cancer 46: 11-17, 2006.
40. Kampe CE, Rosen G, Eilber F, et al: Synovial sarcoma: A study of intensive chemotherapy in 14 patients with localized disease. Cancer 72: 2161-2169, 1993.

41. Rosen G, Forescher C, Lowenbraun S, et al: Synovial sarcoma: Uniform response of metastases to high dose ifosfamide. Cancer 73: 2506-2511, 1994

42. Spurrel EL, Fisher C, Thomas JM, et al: Prognostic factors in advanced synovial sarcoma: an analysis of 104 patients treated at the Royal Marsden Hospital. Ann Oncol 16: 437-444, 2005.

43. Antonescu CR, Kawai A, Leung DH, et al: Strong association of SYT-SSX fusion type and morphologic epithelial differentiation in synovial sarcoma. Diagn Mol Pathol 9: 1-8, 2000.

44. Saito T, Nagai M and Ladanyi M: SYT-SSX1 and SYT-SSX2 interfere with represion of E-cadherin by snail and slung: a potential mechanism for aberrant mesenchymal to epithelial transition in human synovial sarcoma. Cancer Res 66: 6919-1927, 2006. 